Чамурлиев Георгий Омариевич, старший преподаватель агроинженерного департамента Аграрнотехнологического института ФГАОУ ВО РУДН (Российский университет дружбы народов) (РФ, 117198, г. Москва, Миклухо-Маклая, 8), кандидат сельскохозяйственных наук, тел. 8-904-777-48-58, ORCID: http://orcid.org/0000-0002-6410-8438 giorgostsamourlidis@mail.ru

Иленева Светлана Викторовна, доцент кафедры технологий переработки и безопасности пищевых продуктов Волгоградского государственного аграрного университета (400002, г. Волгоград, пр. Университетский, 26), кандидат технических наук, e-mail: sileneva@bk.ru.

Набойченко Константин Викторович, доцент кафедры растениеводства, селекции и семеноводства Волгоградского государственного аграрного университета (400002, г. Волгоград, пр. Университетский, 26), кандидат сельскохозяйственных наук, e-mail: volgauselect@ya.ru

\title{
THE USE OF COMPLEX BIOPREPARATIONS IN CULTIVATION OF MELONS ON THE IRRIGATED LANDS OF THE NORTHERN CASPIAN LANDS
}

\author{
N.V. Tutuma, A.N. Bondarenko, O.V. Kostyrenko \\ Federal State Budget Scientific Institution \\ "Caspian Agrarian Federal Scientific Center of the Russian Academy of Sciences», Astrakhan region \\ Submitted 25.05.2021
}

Received 12.02.2021

\section{Summary}

Results on cultivation of melons with use of microbiological preparations are presented. Optimal options have been identified that contribute to the formation of high yield of the studied crops.

\begin{abstract}
Introduction. The main areas under melon crops are concentrated mainly in the South-East of the Russian Federation, due to climatic conditions. For the first time in the conditions of light chestnut soil on the land use territory of the Caspian Agricultural Scientific Federal Scientific Center of the Russian Academy of Sciences during 2019-2020. a study was carried out on the cultivation of various varieties of watermelon and various varieties of melon using complex of biological products (CBP) in order to obtain high and stable yields with drip irrigation. Materials and methods. The study included 4 varieties of watermelon and 4 varieties of melon. The research material was complex of biological products: CBC (cyanobacterial consortium); CBP $(10702+\mathrm{F}+\mathrm{P})$; Biohumus. (Federal State Budget Institution of Science «Scientific Research Institute of Agriculture of Crimea») The economically valuable traits of the studied varieties cultivated in the arid zone of the Astrakhan region were evaluated. Results and conclusion. As a result of the conducted studies of various varieties and hybrids of the studied crops (watermelon and melon), on average, for two years of study (2019-2020), it was possible to single out the watermelon cultivar Peasant and the melon hybrid Alice F1, which showed the maximum yield level. The highest yield of the watermelon variety was obtained using the option Biohumus + CBP st and amounted to $98.3 \mathrm{t} /$ ha with an average fruit weight of $6.8 \mathrm{~kg}$. For other processing options for the Krestyanin variety, the yield indicators changed slightly. In the melon hybrid Alisa F1, the maximum yield was achieved using a similar version of Biohumus + CBP st. The biological yield was equal to $72.6 \mathrm{t} /$ ha with an average fruit weight of $4.7 \mathrm{~kg}$. Marketability with such indicators was $98 \%$. Presowing soaking of seeds in a solution of Biohumus + CBP st contributed to a significant increase in yield.
\end{abstract}

Keywords: watermelon, melon, biologics, seed soaking, yield.

Citation. Tyutyuma N. V., Bondarenko A. N., Kostyrenko O. V. Use of complex biologics when cultivating melons on irrigated lands of the Northern Caspian Sea. Proc. of the Lower Volga AgroUniversity Comp. 2021. 2(62). 93-101 (in Russian). DOI: 10.32786/2071-9485-2021-02-10.

Author's contribution. All authors of the present study were directly involved in the planning, execution or analysis of this study. All authors of this article have read and approved the submitted final version.

Conflict of interest. The authors declare that there is no conflict of interest. 


\section{***** H3BECTHЯ ***** \\ НИЖНЕВОАЖСКОГО АГРОУНИВЕРСИТЕТСКОГО КОМПАЕКСА \\ НАУКА И ВЫСШЕЕ ПРОФЕССИОНААЬНОЕ ОБРАЗОВАНИЕ \\ УДК 631.5:579.64:631.46 \\ ИСПОЛЬЗОВАНИЕ КОМПЛЕКСНЫХ БИОПРЕПАРАТОВ ПРИ ВОЗДЕЛЫВАНИИ БАХЧЕВЫХ КУЛЬТУР НА ОРОШАЕМЫХ ЗЕМЛЯХ СЕВЕРНОГО ПРИКАСПИЯ}

Н. В. Тютюма, доктор сельскохозяйственных наук, профессор РАH,

А. Н. Бондаренко, кандидат географических наук

О. В. Костыренко, младший научный сотрудник

ФГБНУ Прикаспийский аграрный федеральный научный центр РАН, Астраханская область, Черноярский район, село Солёное Займище

Дата поступления в редакцию 12.02.2021

Дата принятия к печати 25.05.2021

Актуальность. Основные площади под бахчевыми культурами сосредоточены главным образом на юго-востоке РФ, что обусловлено климатическими условиями. Впервые в условиях светло-каштановой почвы на территории землепользования ФГБНУ «Прикаспийский аграрный научный федеральный научный центр РАН» в течение 2019-2020 гг. было проведено изучение возделывания различных сортов арбуза и различных сортов дыни при использовании комплексных биопрепаратов (КБП) с целью получения высоких и стабильных урожаев при капельном способе полива. Материалы и методы. В изучении находились 4 сорта арбуза и 4 сорта дыни. Материалом исследования являлись комплексные биопрепараты: ЦБК; КБП (10702+Ф+П); Биогумус. (ФГБУН «НИИСХ Крыма»). Оценивались хозяйственно ценные признаки исследуемых сортов, возделываемых в условиях аридной зоны Астраханской области. Результаты и обсуждение. В результате проведенных исследований различных сортов и гибрида изучаемых культур (арбуз и дыня) в среднем за два года изучения (2019-2020 гг.) смогли выделить сорт арбуза Крестьянин и гибрид дыни Алиса F1, которые показали максимальный уровень урожайности. Самая высокая урожайность у сорта арбуза была получена на варианте Биогумус+КБП st и составила 98,3 т/га при средней массе плода 6,8 кг. По другим вариантам обработки у сорта Крестьянин показатели урожайности изменялись незначительно. У гибрида дыни Алиса F1 максимальная урожайность была достигнута на аналогичном варианте Биогумус+КБП st. Биологическая урожайность была равна 72,6 т/га при средней массе плода 4,7 кг. Товарность при таких показателях составила 98 \%. Предпосевное замачивание семян в раствоpe Биогумус+КБП st способствовало значительному увеличению урожайности.

Ключевые слова: воздельвание бахчевых культур, комплексные биопрепараты, замачивание семян бахчевых, урожайность бахчевых культур.

Цитирование. Тютюма Н. В., Бондаренко А. Н., Костыренко О. В. (). Использование комплексных биопрепаратов при возделывании бахчевых культур на орошаемых землях Северного Прикаспия. Известия НВ АУК. 2021. 2(62). 93-101. DOI: 10.32786/2071-9485-2021-02-10.

Авторский вклад. Все авторы настоящего исследования принимали непосредственное участие в планировании, выполнении или анализе данного исследования. Все авторы настоящей статьи ознакомились и одобрили представленный окончательный вариант.

Конфликт интересов. Авторы заявляют об отсутствии конфликта интересов.

Введение. Бахчевые культуры получили широкое распространение и пользуются хорошим спросом у населения во всем мире $[1-3,5,8,10]$.

Большое значение при возделывании арбуза и дыни в настоящее время на орошении имеет применение микробиологических препаратов и стимуляторов роста, что в совокупности значительно увеличивает их урожайность $[4,6,7,9,11]$, в связи с чем, целью настоящего исследования явились разработка и выявление оптимального варианта ростостимулирования на примере использования комплексных биопрепаратов при возделывании бахчевых культур (арбуз, дыня) на орошаемых землях Северного Прикаспия. 
Для достижения поставленной цели были поставлены следующие задачи: провести фенологические наблюдения по основным фазам развития арбуза и дыни: всходы, шатрик, плетеобразование, цветение, созревание; изучить в полевом опыте влияние различных комплексных биопрепаратов на рост, развитие и урожайность арбуза и дыни; определить влияние оптимальных вариантов ростостимулирования на продуктивность сортов и массу плодов изучаемых культур; провести учет биологической урожайности путем весового учета на всех вариантах опыта, а также определить товарность плодов в зависимости от вариантов опыта.

На основе проведенных исследований получены экспериментальные данные, осуществлен комплексный подход в изучении использования комплексных биопрепаратов и получения высоких и стабильных урожаев бахчевой продукции. Проведено определение и обоснование оптимального варианта ростостимулирования с учетом почвенно-климатических условий, сортового состава и условий агротехники для аридной зоны Северного Прикаспия.

Материалы и методы. Опыт был заложен в трехкратной повторности по методике Доспехова Б. А. Размещение вариантов систематическое. Площадь опыта 1 культуры - 960,0 м², площадь делянки под 1 вариантом - 240,0 м². Площадь 1 учётной делянки - 80,0 м² (Белик В. Ф., 1982). Общая площадь под опытом двух культур (арбуз, дыня) - 1920,0 м². Способ полива - капельное орошение.

Схема опыта:

1. І вариант - контроль (без удобрений).

2. II вариант - ЦБК.

3. III вариант - КБП $(10702+\Phi+П)$.

4. IV вариант - Биогумус +КБП st.

Для выполнения поставленных задач проводились полевые учёты, наблюдения и измерения с использованием методики полевого опыта Доспехова Б. А.; методики опытного дела в овощеводстве и бахчеводстве под редакцией Белика В. Ф., Литвинова С. С., методики Государственного сортоиспытания сельскохозяйственных культур 2015 г.

Учет урожая проводился путем взвешивания всей продукции с делянки - как товарной, так и нетоварной. В товарной части урожая учитывалась отдельно стандартная и нестандартная продукция. Стандартную продукцию определяли согласно требованиям ГОСТ 7177-80. Средняя масса плода определялась при каждом сборе.

Объект исследований: арбуз сортов Кримсон Свит, Фермер, Талисман, Крестьянин и дыня сортов Эфиопка, Лада, Виктория, Алиса F1.

Материалом исследования служили комплексные жидкие биопрепараты: ЦБК; КБП (10702+Ф+П); Биогумус. (ФГБУН «НИИСХ Крыма»).

Комплекс биопрепаратов (КБП) включает симбиотические, ассоциативные с растением азотфиксирующие, фосфатмобилизирующие и биопротекторные микроорганизмы с функциональными свойствами биопрепаратов: Ризобофита, Диазофита, Фосфоэнтерина и Биополицида - и характеризуется комплексным влиянием на сельхозкультуры, повышая урожайность и качество продукции. Жидкая форма препарата содержит живые культуры азотфиксирующих, фосфатмобилизирующих микроорганизмов и бактерий-антагонистов фитопатогенов, их метаболиты и остатки культурной среды.

ЦБК - биопрепарат на основе полифункционального цианобактериального консорциума, улучшает азотное и фосфорное питание, стимулирует рост и развитие растений, повышает устойчивость растений к биотическим и абиотическим стрессовым факторам, активизирует почвенные процессы в агроценозах. 
Биогумус (вермикомпост) - экологически чистое органическое удобрение, продукт переработки навоза КРС популяцией технологического червя «Старатель». Это концентрированное удобрение содержит в сбалансированном сочетании целый комплекс необходимых питательных веществ и микроэлементов, ферменты, почвенные антибиотики, витамины, гормоны роста и развития растений. В нем большое количество гуминовых веществ. Биогумус - уникальное микробиологическое удобрение, в котором обитает полезное сообщество почвенных микроорганизмов, создающих плодородие земель.

Для обработки семян каждый препарат суспендировали (разводили) в воде. Общий рабочий раствор жидкости составлял 1-2 \% от массы семян. Гектарная норма расхода препарата - 100 мл.

Готовую суспензию равномерно наносили на семена. Семена высевали в открытый грунт в течение суток после обработки (согласно рекомендациям ФГБУН «НИИСХ Крыма»). Дополнительно в течение вегетации было внесено с поливной водой $\mathrm{N}_{60} \mathrm{P}_{90} \mathrm{~K}_{45}$.

Результаты и обсуждение. Предшественником для посева бахчевых культур являлся яровой ячмень сорта Ратник. Осенняя вспашка проводилась на глубину 22-24 см плугом ПЛН-4-35. Весенняя обработка почвы началась по мере физического созревания почвы. Весной вспашка осуществлялась на глубину 22-24 см плугом ПЛН-4-35. Закрытие весенней влаги и одновременное выравнивание поверхности поля проводились тяжелыми дисковыми боронами по диагонали участка. Всего было проведено 2 культивации культиватором КПС-5. За день до посева была проведена обработка фрезой Ф-200 + МТ3-80. Далее была проведена раскладка капельных лент.

Май и июнь 2019 гг. характеризовались малым количеством осадков $-4,9$. . 8,9 мм. Среднесуточная температура воздуха изменялась подекадно несущественно. Среднесуточная температура в мае была равна $26,0^{\circ} \mathrm{C}$, в июне $-24,0^{\circ} \mathrm{C}$. ГТК был равен 0,1 . Июль характеризовался самым максимальным количеством осадков 58,0 мм. Среднесуточная температура воздуха была равна $24,0{ }^{\circ} \mathrm{C}$. ГТК был равен 0,7 . Относительная влажность воздуха 53 \%. Август характеризовался полным отсутствием осадков во второй и третьей декадах месяца. За месяц выпало всего 7,0 мм. Среднесуточная температура воздуха составляла всего $+22,9^{\circ} \mathrm{C}$. Сумма активных температур $>10{ }^{\circ} \mathrm{C}$, была равна $+719,9{ }^{\circ} \mathrm{C}$. ГТК $=0,1$ Относительная влажность воздуха $41 \%$. В сентябре выпало 37,4 мм, среднесуточная температура воздуха была равна $+15,8{ }^{\circ} \mathrm{C}, \Gamma T К=0,8$, относительная влажность воздуха $52 \%$.

Среднесуточная температура воздуха в мае 2020 гг. составляла $+16,2{ }^{\circ} \mathrm{C}$. Относительная влажность воздуха - $62,6 \%$. Необходимо отметить, что именно в мае выпало максимальное количество осадков за весь период вегетации 41,5 мм, большая их часть - во вторую декаду месяца 21,1 мм. Сумма активных температур была равна $+505,1{ }^{\circ} \mathrm{C}$. Июнь характеризовался относительно высокими среднесуточными температурами, которые варьировали от $+22,0$ до $+24,8^{\circ} \mathrm{C}$. Осадков выпало всего 14,1 мм. ГТК был равен 0,2.

Июль был очень жарким, в некоторые дни температура воздуха поднималась выше $+40,0{ }^{\circ} \mathrm{C}$, но в среднем за месяц она составляла $+28,1^{\circ} \mathrm{C}$. За июль выпало самое минимальное количество осадков - 0,7 мм. При таких показателях ГТК был равен 0 , что характерно для острозасушливого периода. Август аналогично июлю характеризовался очень жаркими днями. Среднесуточная температура составляла $+23,2{ }^{\circ} \mathrm{C}$. Осадки тоже были минимальными - 7,2 мм, ГТК =0,1. Среднесуточная температура воздуха в сентябре была равна $+18,3{ }^{\circ} \mathrm{C}$. Осадки полностью отсутствовали. Сумма активных температур за месяц была равна $+550,3{ }^{\circ} \mathrm{C}$, относительная влажность воздуха $-39,0 \%$, ГТК $=0$. 

НАУКА И ВЫСШЕЕ ПРОФЕССИОНААЬНОЕ ОБРАЗОВАНИЕ

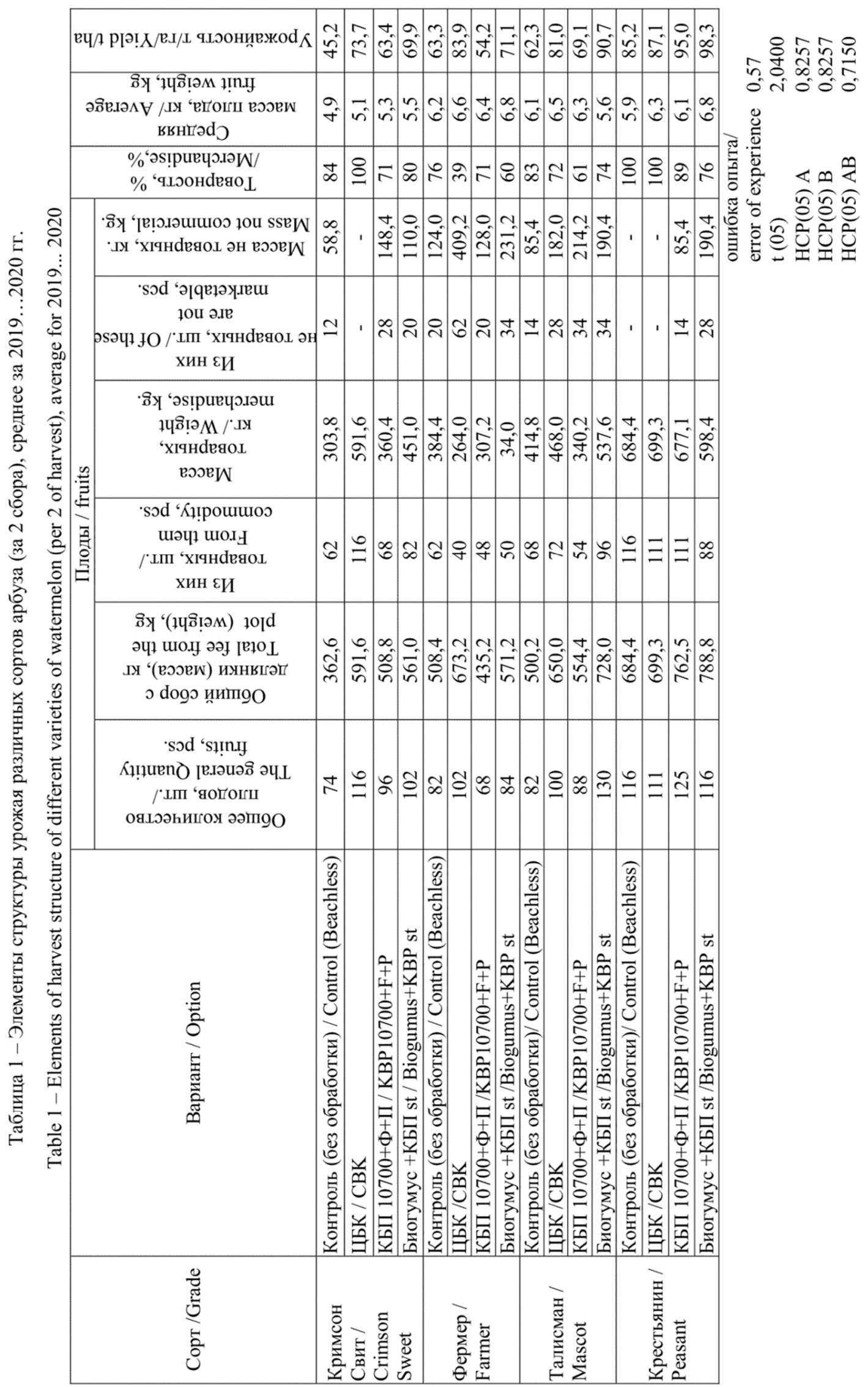




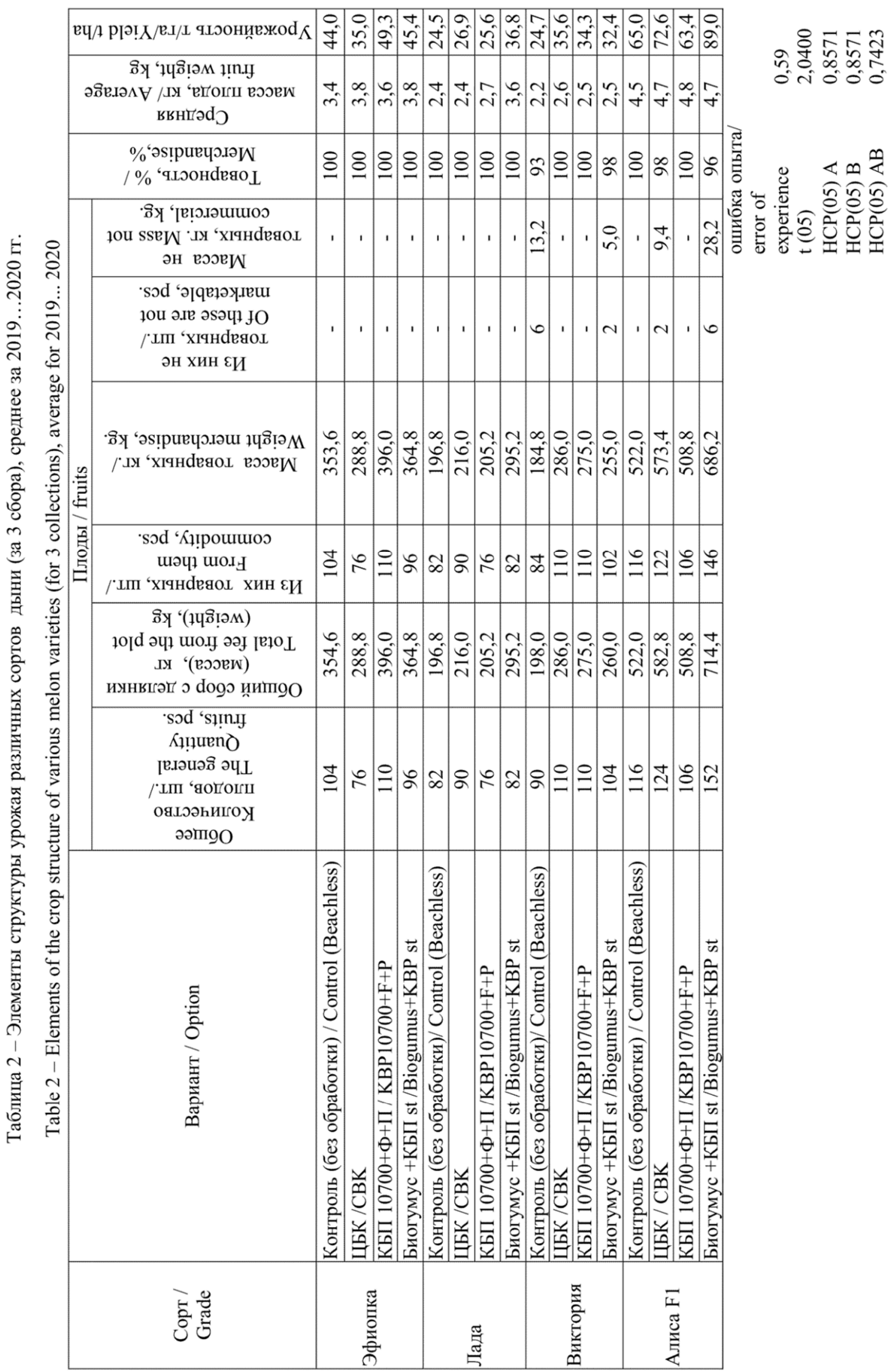


В результате проведенных фенологических наблюдения у различных сортов арбуза и дыни было выявлено, что различий по наступлению фенологических фаз по вариантам опыта не наблюдалось.

Арбузы высевали в течение двух лет изучения во второй декаде мая 18.05...19.05 при достижении оптимальных температур воздуха и почвы. Начало массовых всходов было отмечено через 14 сут. после посева. В фазу шатрик растения вступили через 28 суток после всходов. Цветение было зафиксировано в первой декаде июля - 04.07...06.07, образования плодов во второй декаде июля - 21.07... 23.07. Первый сбор был осуществлен во второй декаде августа 17.08...18.08. Всего было осуществлено 2 сбора за весь вегетационный период.

Различные сорта дыни, аналогично, были высеяны $18.05 \ldots 20.05$. Начало фазы массовых всходов было отмечено 05.06...07.06. Фаза шатрика была зафиксирована во второй декаде июня. Начало фазы цветения варьировало в зависимости от года исследований 05.07...07.07. Образование плодов было отмечено во второй декаде июля. Первый сбор дыни был осуществлен во второй - третьей декадах августа. Всего было осуществлено три сбора.

По результатам проведенных исследований: максимальные показатели по элементам структуры урожая при возделывании различных сортов арбуза с использованием предпосевного замачивания семян комплексными жидкими биопрепаратами были получены на варианте с применением Биогумус+КБП у сортов Талисман и Крестьянин. Общий сбор с делянки по данным сортам варьировал от 728,0 до 788,8 кг, масса товарных плодов составляла 537,6...598,4 кг с делянки. Товарность находилась в диапазоне 74...76 \%. Средняя масса плода была равна 5,6...6,8 кг, урожайность 90,7 ..98,3 т/га (таблица 1).

У сортов дыни прослеживалась аналогичная тенденция, наиболее эффективно себя проявил вариант с предпосевным замачиванием семян баковой смесью Биогумус+КБП. По данному варианту высокоурожайными в изучении оказались сорт дыни Эфиопка и гибрид Алиса F1. Общий сбор с делянки был равен 364,8...714,4 кг. Количество товарных плодов составляло от 96 до 146 шт., товарность 96..100\%. Средняя масса плода была равна $3,8 \ldots 4,7$ кг, урожайность $-45,4 \ldots 89,0$ т/га (таблица 2).

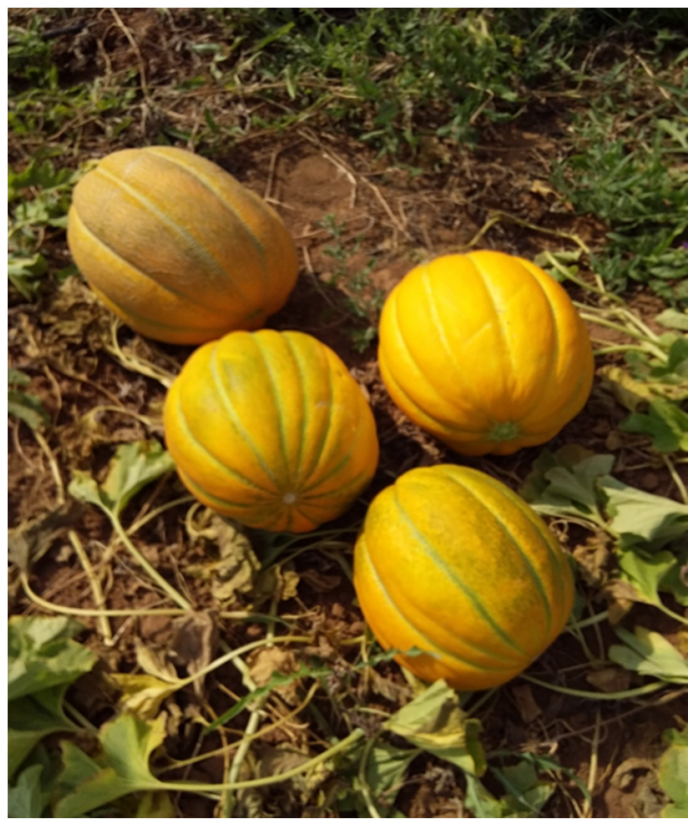

Рисунок 1 - Дыня сорт Эфиопка

Figure 1 - Melon class Ethiopian

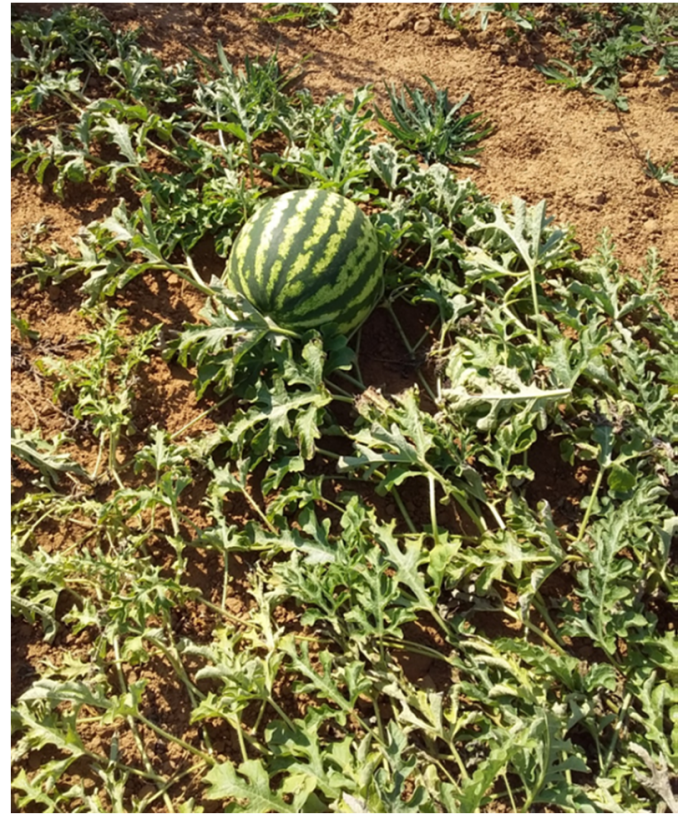

Рисунок 2 - Арбуз сорт Крестьянин

Figure 2 - Watermelon variety Peasant 


\section{Выводы:}

1. Предпосевное замачивание семян изучаемых бахчевых культур биопрепаратами на основе ассоциативных азотфиксирующих микроорганизмов из расхода (раствор жидкости составлял 1-2 \% от массы семян, гектарная норма расхода препарата - 100 мл) улучшило питание растений арбуза и дыни на первых этапах развития, а дополнительное фоновое питание из расчёта $\mathrm{N}_{60} \mathrm{P}_{90} \mathrm{~K}_{45}$ способствовало увеличению урожайности на 10-30 \%.

2. Максимально положительный эффект по показателям урожайности был получен от баковой смеси Биогумус + КБП st. На основании полученных результатов исследований исполнители считают возможным рекомендовать его для применения на культуре арбуз и дыня для почвенно-климатических условий аридного климата СевероЗападного Прикаспия.

\section{Библиографический список}

1. Быковский Ю. А., Варивода Е. А. Перспективные сорта бахчевых культур для юга России // Картофель и овощи. 2017. № 9. С. 39-40.

2. Варивода Е. А., Корнилова М. С., Варивода Г. В. Результаты сортоиспытания новых сортов дыни в условиях Волгоградского Заволжья // Овощи России. 2018. № 2 (40). С. 61-64.

3. Варивода О. П., Масленникова Е. С. Оценка и подбор исходного материала для создания гибридов дыни с комплексной устойчивостью к антракнозу и мучнистой росе // Овощи России. 2019. № 5. С. 20-24. https://doi.org/10.18619/2072-9146-2019-5-20-2.

4. Рябчикова Н. Б., Колебошина Т. Г., Суслова В. А. Влияние стимуляторов роста на урожайность и качество плодов арбуза в условиях открытого грунта Волгоградского Заволжья // Труды Кубанского государственного аграрного университета. 2018. № 3 (72). С. 315-320.

5. Сравнительная оценка новых сортов и гибридных популяций дыни / Т. Г. Колебошина, Н. Г. Байбакова, Е. А. Варивода, Г. С. Егорова // Известия НВ АУК. 2020. № 2 (58). С. 57-65.

6. Сравнительная оценка различных видов удобрений и способов их применения при выращивании бахчевых культур в условиях Волгоградского Заволжья / Т. Г. Колебошина, С. Д. Фомин, Н. Б. Рябчикова, О. Г. Вербитская // Известия НВ АУК. 2020. № 3 (59). С. 107-116.

7. Эффективность применения новых видов и норм водорастворимых удобрений в технологии выращивания арбуза столового в условиях Волгоградского Заволжья / Н. Б. Рябчикова [и др.] // Труды Кубанского государственного аграрного университета. 2019. № 81. С. 173-177.

8. Chemical properties and microbial responses to biochar and compost amendments in the soil under continuous watermelon cropping / Y. Cao, Y. Ma, D. Guo, Q. Wang, G. Wang // Plant Soil Environ. 2017. V. 63. P. 1-7.

9. Effect of Bicyclopyrone on Triploid Watermelon in Plasticulture /M. B. Bertucci, K. M. Jennings, D. W. Monks, D. L. Jordan, J. R. Schultheis, F. J. Louws, M. D. Waldschmidt // Weed Technology. 2018. V. 32. I. 4 . P. 439-443.

10. Genetic diversity and population structure of core watermelon (Citrullus lanatus) genotypes using DArTseq-based SNPs / X. Yang, R. Ren, R. Ray, J. Xu, P. Li, M. Zhang, G. Liu, X. Yao, A. Kilian // Plant Genetic Resources. 2016. V. 14. Is. 3. P. 226-233.

11. Glyoxylate cycle and reactive oxygen species metabolism are involved in the improvement of seed vigor in watermelon by exogenous GA3 /Y. He, Z. Ye, Q. Ying, Y. Ma, Y. Zang, H. Wang, Y. Yu, Z. Zhu // Scientia Horticulturae. 2019. V. 247. P. 184-194.

\section{Conclusions:}

1. Pre-sowing soaking of seeds of the studied melon crops with biologics based on associative nitrogen-fixing microorganisms from the flow rate (the liquid content was $1-2 \%$ of the seed weight, the hectare rate of drug consumption was $100 \mathrm{ml}$ ) improved the nutrition of watermelon and melon plants at the first stages of development, and additional background nutrition at the rate of N60P90K45 contributed to an increase in yield by $10-30 \%$.

2. The maximum positive effect on yield indicators was obtained from the tank mixture Biohumus + CBP st. Based on the results of the research, the performers consider it possible to recommend it for use on the watermelon and melon culture for the soil and climatic conditions of the arid climate of the North-Western Caspian region. 


\section{References}

1. Bykovskij Yu. A., Varivoda E. A. Perspektivnye sorta bahchevyh kul'tur dlya yuga Rossii // Kartofel' i ovoschi. 2017. № 9. P. 39-40.

2. Varivoda E. A., Kornilova M. S., Varivoda G. V. Rezul'taty sortoispytaniya novyh sortov dyni v usloviyah Volgogradskogo Zavolzh'ya // Ovoschi Rossii. 2018. № 2 (40). P. 61-64.

3. Varivoda O. P., Maslennikova E. S. Ocenka i podbor isxodnogo materiala dlya sozdaniya gibridov dyni s kompleksnoj ustojchivost'yu k antraknozu i muchnistoj rose // Ovoschi Rossii. 2019. № 5. P. 20-24. https://doi.org/10.18619/2072-9146-2019-5-20-2.

4. Ryabchikova N. B., Koleboshina T. G., Suslova V. A. Vliyanie stimulyatorov rosta na urozhajnost' i kachestvo plodov arbuza v usloviyah otkrytogo grunta Volgogradskogo Zavolzh'ya // Trudy Kubanskogo gosudarstvennogo agrarnogo universiteta. 2018. № 3 (72). P. 315-320.

5. Sravnitel'naya ocenka novyh sortov i gibridnyh populyacij dyni / T. G. Koleboshina, N. G. Bajbakova, E. A. Varivoda, G. S. Egorova// Izvestiya NV AUK. 2020. № 2 (58). P. 57-65.

6. Sravnitel'naya ocenka razlichnyh vidov udobrenij i sposobov ih primeneniya pri vyraschivanii bahchevyh kul'tur v usloviyah Volgogradskogo Zavolzh'ya / T. G. Koleboshina, S. D. Fomin, N. B. Ryabchikova, O. G. Verbitskaya // Izvestiya NV AUK. 2020. № 3 (59). P. 107-116.

7. \}ffektivnost' primeneniya novyh vidov i norm vodorastvorimyh udobrenij v tehnologii vyraschivaniya arbuza stolovogo v usloviyah Volgogradskogo Zavolzh'ya / N. B. Ryabchikova [i dr.] // Trudy Kubanskogo gosudarstvennogo agrarnogo universiteta. 2019. № 81. P. 173-177.

8. Chemical properties and microbial responses to biochar and compost amendments in the soil under continuous watermelon cropping / Y. Cao, Y. Ma, D. Guo, Q. Wang, G. Wang // Plant Soil Environ. 2017. V. 63. P. 1-7.

9. Effect of Bicyclopyrone on Triploid Watermelon in Plasticulture /M. B. Bertucci, K. M. Jennings, D. W. Monks, D. L. Jordan, J. R. Schultheis, F. J. Louws, M. D. Waldschmidt // Weed Technology. 2018. V. 32. I. 4 . P. 439-443.

10. Genetic diversity and population structure of core watermelon (Citrullus lanatus) genotypes using DArTseq-based SNPs / X. Yang, R. Ren, R. Ray, J. Xu, P. Li, M. Zhang, G. Liu, X. Yao, A. Kilian // Plant Genetic Resources. 2016. V. 14. Is. 3. P. 226-233.

11. Glyoxylate cycle and reactive oxygen species metabolism are involved in the improvement of seed vigor in watermelon by exogenous GA3 /Y. He, Z. Ye, Q. Ying, Y. Ma, Y. Zang, H. Wang, Y. Yu, Z. Zhu // Scientia Horticulturae. 2019. V. 247. P. 184-194.

\section{Author's Information}

Tyutyuma Natalya Vladimirovna, Doctor of Medical Sciences, Professor of the Russian Academy of Sciences, Director of FSBNU PAFNTS RAS. 416251. Astrakhan region, Chernoyarsky district, sq. North 8. E-mail. pniiaz@ mail.ru (ORSID ID № 0000-0001-6582-2628)

Bondarenko Anastasia Nikolaevna, K. N., Head of the Laboratory of Agricultural Technologies of Vegetable Crops. FSBNU PAFNTS RAS 416251. Astrakhan region, Chernoyarsky district, sq. North 8. E-mail. pniiaz@ mail.ru. (ORSID ID № 0000-0003-4816-5667)

Kostyrenko Oksana Vladimirovna, m.n.s. Laboratories of agricultural technologies of vegetable crops. FSBNU PAFNTS RAS 416251. Astrakhan region, Chernoyarsky district, sq. North 8. E-mail. pniiaz@ mail.ru (ORSID ID № 0000-0002-9650-9674)

\section{Информация об авторах}

Тютюма Наталья Владимировна, доктор сельскохозяйственных наук, профессор РАН, директор ФГБНУ «ПАФНЦ РАН». 416251. Астраханская область, Черноярский район, кв.-л Северный 8). Еmail.pniiaz@mail.ru n(ORSID ID № 0000-0001-6582-2628)

Бондаренко Анастасия Николаевна, кандидат географических наук, зав. лабораторией агротехнологий овощных культур. ФГБНУ «ПАФНЦ РАН» (416251. Астраханская область, Черноярский район, кв.-л Северный 8. E-mail. pniiaz@ mail.ru. (ORSID ID № 0000-0003-4816-5667)

Костыренко Оксана Владимировна, младший научный сотрудник лаборатории агротехнологий овощных культур. ФГБНУ «ПАФНЦ РАН» (416251. Астраханская область, Черноярский район, кв.л Северный 8). E-mail. pniiaz@ mail.ru (ORSID ID № 0000-0002-9650-9674) 